\title{
Analysis of Causes and Consequences of Road Traffic Accidents: The Case of Gamo Gofa Zone, Southern Ethiopia
}

\author{
Lidetu Alemu Anjulo (Assistant professor) \\ Lecturer, department of management, Wolaiita Sodo University, Southern Ethiopia \\ p.o.box: 138 Wolaita sodo \\ Eyasu Parde Kuma \\ MBA graduate and Gamo Zone Police Administration Officer \\ Bewunetu Zewude G/Meskel \\ Research and Community Services Directorate Paradise Valley University College, Shashamene Ethiopia
}

\begin{abstract}
Transport systems provide mobility, access and other benefits such as facilitating the productivity of the other sectors of the economy. However, it also the main causes fatalities, injuries and property damage. This needs proper management of the system. The objective of this study was to find out the causes and the consequences of road traffic accident in Gamo Gofa Zone. For this end the questionnaire was distributed to 324 respondents and also the interview was conducted to passengers, officers and personal observations were implemented. Further road accident-related traffic police and transport and road development department as the secondary sources and the simple random sampling was used. The analysis was done by employing descriptive statistics. The results accomplished from the descriptive analysis were shown that a combination of different factors and actors in the transport sector has massively contributed to the incidence of road traffic accident in Gamo Gofa Zone. Some of these include drivers' mistakes resulted from behavioral problems, wrong crossing of the road by pedestrians and not giving priorities to vehicles and poor traffic regulation enforcement. Implementing different awareness raising mechanisms for the communities, capacity building and proper regulation enforcement mechanisms are suggested to decrease accidents in the zone.
\end{abstract}

Keywords: - Accident, Causes, Consequences, transport system, management

DOI: $10.7176 / \mathrm{EJBM} / 11-28-03$

Publication date:October $31^{\text {st }} 2019$

\section{Introduction}

\subsection{Background of the Study}

One of the Inverse impacts of transport service is a traffic accident. It is mostly caused by over speeding of vehicles. Motorists that run more than the permitted standard speed through roads may be strike other vehicles. The statistics revealed and showed $30 \%$ of registered accidents are caused by over running (Akongbota, J. 2011). An increasing population requires access to business activities, education, employment and recreational opportunities (Fanueal, S. 2006). The transportation system has a great influence and impact on regional patterns of development, economic viability, environmental impacts, and on maintaining socially acceptable levels of quality of life. It is not surprising to find that considerable resources continue to be expended by government agencies in the planning and development of more effective transportation services for transportation is a fundamental function of human society (Fanueal, S. 2006)

To a large extent, the economic and social development of nations is revolved on the transportation system. In fact the recognition of global trade objectives is also relies on transportation and that the linkage between transportation and economic development is continuing to be a progressive for global economic prosperity. Transport Systems provide mobility, access and other benefits such as facilitating the productivity of the other sectors of the economy and plays a major role in the life of an individual, societies as well as countries' economic development. It is one of the basic requirements of the people functioning of society as its demand is highly related to the movement of people from one place to another. Hence, transportation infrastructures are powerful determinants of the economic and social wellbeing of all cities, towns and communities (Gifford, J, 2003).

It is acknowledged fact that of all modes of transportation, road transport is the nearest to people in both developing and developed countries. Its major advantage compared with others, its flexibility which across it to operate from door to door over short distances at the most competitive price (Atnafseged, 1996). However, the boost in road transportation has placed an extensive saddle on the people's lives (WHO, 2009). Road traffic accidents have turned out to be a huge global public health and development problem killing almost 1.2 million people a year and injuring or disabling between 20-50 million people more. The statistical profile reflects that in 2002, an estimated 1.2 million people were killed and 50 million injured in road-traffic crashes worldwide, costing the global community about US \$ 518 billion (Pedenet.Al, 2004). The International Federation of Red Cross and 
Red Crescent Societies have described the situation as "a worsening global disaster destroying lives and livelihoods, hampering development and leaving millions in greater vulnerability" (Cater and Walker, 1998). The fundamental grounds for this rapid traffic accident occurrence is insufficient road networks, slow road construction and maintenance, rapid traffic growth, a shortage of parking space in the narrow streets, as well as ineffective traffic management and enforcement. Without appropriate action, road traffic accident and its resultant injuries are predicted to escalate dramatically as a global burden of disease by 2020, particularly in rapidly-motorizing countries.

This study was planned to conduct a research study on the road traffic accident in the GamoGofa Zone, SNNPR. The principal motive behind this research is that the current road accident rate in the zone. The study primarily attempts to assess the causes and the consequences of road accidentswhich primarily involved in the accident during 2006-2010 periods using descriptive data analysis method.

\subsection{Statement of the Problem}

Most major cities worldwide have been characterized by the phenomenon of steadily increasing urbanization accompanied by exponentially increasing private motorized vehicles. This has led to congested roads and expansive cities with travelers having to travel very long distances to and from work (Sida, 2009). Globally about 1.2 million persons were killed on the road traffic accident and additional 20-50 million were injured. Road traffic injures were $11^{\text {th }}$ leading cause of death accounted for 2.1 percent of all death. Studies have revealed that Ethiopia loses about $\$ 65$ million annually due to traffic accidents WHO (2011). In addition the victims are mainly public transport travelers in the working age group (18-30 years) (Daniel, 2014). Statistics from the Federal police shows that in Ethiopia, with the GTP coming to an end in 2015, traffic accident death toll stands at 72 deaths per 10,000 vehicle accidents annually (Federal police report, 2015). This report also depicted that among the causes of accident in the country are ignoring traffic laws, illegal driving, over speeding and drink driving is frequent phenomena.

The Gamo Gofa Zone is no exception and experiences area-wide traffic disorder on a daily basis. There are $1681.2 \mathrm{~km}$ of classified roads in Gamo Gofa Zone, $392 \mathrm{~km}$ of which are paved. About 4.3 percent of the network is classified as primary roads and has some of the most trafficked arterials that link Gamo Gofa Zone with its neighbor's Zones and Special Districts. Despite huge investments by federal and regional as well as zonal administration in road infrastructure, the problem is just worsening. In Gamo Gofa Zone, 59 people are killed in road traffic accidents each year and as many as 73 are injured, and damaged 9,716,439 Birr properties.GGZ Traffic Police Report (2018). This implies that road traffic accident has a negative effect on public and individual property.

\subsection{Objectives of the Study}

\subsubsection{General Objective of the Study}

The general objective of this study was to assess the causes of road traffic accident and its consequences on the life and property of the community in Gamo Gofa Zone over the period of 2004-2018.

\subsubsection{Specific Objective of the Study}

The thesis was bounded by specific objectives as follows.

1. To analyze the level of road traffic accident over the period of 2014-2018

2. To identify the main cause of the road accident in the Zone.

3. To examine the consequences of road traffic accident in the Gamo Gofa Zone.

\subsection{Research Questions}

In light of this concern, the study was tried to answer the following basic research questions.

* What is the current level of road traffic accident in the Gamo Gofa Zone?

* What are the causes that are leading to a road traffic accident?

* What are the consequences of road traffic accident in the Zone?

\section{Literature Review}

\subsubsection{Major Causes of Road Traffic Accident (RTA)}

There are three major classes of causes of road traffic accidents; road user error/human factors, vehicle defects and road condition or environmental factor. Among the most major factors, is the human factor of which drivers' errors take the majority of blames? Drivers' errors that are hazardous include driving too fast, failing to give priority to pedestrians and other vehicles, improper over taking and driving following too close. All of which could result from aggressive or irresponsible behavior, deficient actions, perceptual errors or impairments (Iles, 2005).

\subsubsection{Major Considerations and Guidance While Providing Pedestrian Facilities at Sidewalks and} Crossings

In different literatures reviewed there were many considerations to be taken into account while providing pedestrians facilities at sidewalk and crossings that can be used as a principles, manuals and directives. For instance, 
according to NYC Department of City Planning (2006), the pedestrian characteristics such as age, gender, trip purposes, pedestrian size and the like were used as factors to be taken into considerations while providing the facilities so as to make the movement safer and convenient at any locations in the city. Additionally, the organization was also specified the location characteristics at sidewalks and crossings such as width, obstructions, landscapes, street furniture, street lights, traffic/pedestrian signs, markings, curbs, and so on has to be audited before deciding the installation of particular facilities in the city. Furthermore, according to Laura McNeil (2012), in his book- Steps to a Walk able Community' he stated that Planners and Engineers working on pedestrian facilities have to have guidance for the implementation of their pedestrian facilities project. Accordingly, the identified guidance used before providing the pedestrians facilities were: survey of the existing conditions; perform in-field assessments of existing conditions; address need for safe and accessible street crossings between sidewalks; analyze sidewalk conditions in relation to census and land use data; and determine appropriate sidewalk widths based on existing volumes of people and adjacent land uses.

\subsubsection{Social and Economic Costs of Road Traffic Accidents}

A Road traffic accident causes emotional, physical and economic harm. There is a moral imperative to minimize such losses. A case can also be made for reducing crash deaths on economic grounds, as they consume massive financial resources that countries can ill afford disabled by a road traffic crash there are many others deeply affected.

Many families are driven into poverty by the cost of prolonged medical care, the loss of a family breadwinner or the extra funds needed to care for people which disabilities. Road crash survivors, their families, friends and other caregivers often suffer adverse social, physical and psychological effects.

Worldwide, about 1.2 million, persons are killed in road traffic accidents every year, 20 million to 50 million more are injured or disabled in these accidents. Globally the economic cost of road traffic accidents is about U.S \$518 billion (WHO, 2009).

Ethiopia has one of the highest fatality rates per vehicle in the world. It is in excess of 72 fatalities per 10,000 vehicles. It is also losses about US \$ 65, million annually due to traffic accidents (Federal Police, 2015).

\subsubsection{Empirical Review}

Ethiopian Growth and Transformation Plan (GTP one) is directed towards achieving long term Vision and sustaining the rapid and broad based economic growth and end poverty from the country, Road transportation infrastructure building the issues that need attention includes: increase the effectiveness of the transport system so that the cost of transportation will decrease and increase the private sector's capacity and role in service provision; make the system more flexible and competent for efficient service delivery by restructuring the sector and improving the way it is working; and, make available all weather roads for the rural people so that the time they spent traveling will be saved and invested in other activities for more productivity. -Road density (Km/1000km square) from 44.5 in 2010 growing 100.4 in 2015 , Road density in population ( $\mathrm{km} / 1000$ population) from 0.64 in 2010 growing 1.3 in 2015. Time taken to reach the nearest all weather roads per hour, 3.7 hour in 2010 improving to 1.4 in 2015.(MoFED, 2010/15).

As a result of the RSDP investment, the total road network in Ethiopia has increased on average by about $4.2 \%$ each year. By June 2010, the total classified road network had increased to 48,793 $\mathrm{km}$ (excluding community roads). This is an increase of some 22,243 km from the launch of the program in June 1997, giving a road density of $44.4 \mathrm{~km}$ per $1000 \mathrm{~km} 2$ and $0.58 \mathrm{~km}$ per 1000 population. By the end of GTP One period, the road network is expected to reach $136,004 \mathrm{~km}$, increasing the proportion of road in acceptable condition to $86.7 \%$ in $2014 / 15$. (MoFED, 2010/15).

The Government has initiated the railway network development during GTP One. The network planning using GIS and satellite images have been completed the target is to construct 2,395 $\mathrm{km}$ of national railway network by $2014 / 15$, of which around $1,808 \mathrm{~km}$ will be completed. Additionally, $34 \mathrm{~km}$ light railway network shall be completed in Addis Ababa. The development of national and light railways shall play an important role in cost effective and time efficient means of transporting bulk inputs, produce and people. It is also a low or carbon neutral means of transport since it uses the hydropower electric grid powered energy for locomotion.

Ethiopia faces the following challenges that the country plans to address in the medium and long term time frame:- poor services provision and infrastructure development due to scattered rural settlement poor quality of road design, delays of road project construction, shortage of skilled man power External factors such as the slow and declining flow of new and additional financial resources from developed countries to developing countries (as promised by the international community) is also affecting progress towards sustainable development in Ethiopia (MoFED, 2010/15)

The road traffic accident has significant impact on the global population being the 9 th leading cause of death in WHO (2004) and projected it would be the fifth leading cause of death in 2030. Data found from WHO (2009) report indicates the road traffic accident is the leading cause of death among people aged 5-44 which has a greater impact on the global economy and health of the population.

Ampanozi G, Benos et. al (2011) analyzed fatal motor vehicle collisions in Macedonia, Greece, the country 
ranked seventh highest position in road crash fatalities among 38 countries in Europe, and found that $266(85.26 \%)$ of the total were males and almost $60 \%$ of fatalities were among drivers followed by $22.76 \%$ Passengers and $18.59 \%$ pedestrians, $49 \%$ of the pedestrian victims were aged over 65 years, followed by people under the category of $35-$ 44 years.

Consumption of alcohol was responsible cause for 87 (28\%) fatality cases. This finding is the same with the data found in the study conducted in New York City, by (L Nicaj et al, 2006) in which pedestrians aged above 65 years $(48 \%)$ and female were victims in the largest developed countries and most fatalities occur during day time and weekdays. Lankarani et al showed the same result in Shiraz, Iran, another study in Iran the trend shows increasing and male to female ratio is 4:1 According to WHO (2009) reported in with USA Majority of road traffic crash victims were Drivers $62 \%$, then passengers $26 \%$ and the least were pedestrians which account $12 \%$ of the total in the contrary most fatalities on the road happened during night time, weekend and holidays. Unlike USA the one among high income countries, China, which also is the leading populated country, has a high mortality of pedestrians $(24.6 \%)$ and passengers $(24.1 \%)$, the rest were motorcyclists $(22.0 \%)$ may be attributed to the number of highly populated pedestrians, large proportion public transport users and high number of motorcyclists in the country.

\subsubsection{Trends in Road Traffic Injuries in Africa}

According to Mekky A. (1985) vehicles are few in number in relation to the inhabitants in Africa. Less than one licensed vehicles are providing transport services in Africa for 100 people, but 60 people for one licensed are in high income countries. Insecurity management of the vehicles leads a weak fleet of transportation in developing countries. The fleet problem shows, for example, the report indicates that $400 \%$ increase in road deaths in Nigeria between the years of $1960 \mathrm{~s}$ and1980s.As road traffic Management Corporations aid recorded, reported data from developing countries show that it is only when a development threshold is achieved that the road mortality starts to decrease. Such a threshold is far from being reached in sub-Saharan Africa. Indeed, in South Africa, the most developed African country, there were already 17 licensed vehicles per 100 inhabitants in 2005, and no decline in road traffic deaths has been observed so far.

\subsubsection{Crash and Casualty Characteristics}

According to Odero W, Garner P, Zwi A (1997), road traffic deaths between $41 \%$ and $75 \%$ is accounted for pedestrians of all in developing countries. In our continent, passengers of public transportation are the most victimized. Pedestrians alone accounted for 55\% of road traffic deaths in Mozambique in the 1993-2000 period, and $46 \%$ of road traffic deaths in Ghana between 1994 and 1998. This large disadvantaged road users caused by using traffic mix of inappropriate usage of roads (pedestrians, cyclists, motorbikes, cars, and trucks) travelling within the same road at the time.

The seriousness of road traffic crash is a large amount in Africa than anywhere else, because many susceptible road users are involved, but also because of the weak transportation services provision such as overcrowding, and hazardous vehicle environments (Afukaar FK, Antwi P2003).

\subsubsection{Cause of Traffic Accident in Ethiopia}

Numerous studies have been conducted to investigate the causes and consequences of road traffic accidents both locally and internationally. Haile M. and Demeke L. (2014), were conducted a research on factors that affect road traffic accidents in Bahir Dar city, North Western Ethiopia. By employing descriptive statistics, Chi-square and Binary logistic regression methods, they have been found that drivers giving priority stated by the law, pedestrian's manner while crossing the road, drivers usage of seat belt has significant causes for the occurrence of traffic accidents in the city. Pedestrian's manner while crossing the road was also one of the considerable factor for the occurrence of road traffic accidents in Bahir Dar city. The other local study was conducted by Fanueal S. (2006), has analyzed traffic accidents, and develops a computer-based traffic simulation for the route selection in Addis Ababa. His study suggested that a method to predict accidents by considering physical and traffic characteristics of each road. For this, he looked atthe road-characteristic causes to accidents of roads and selected roadcharacteristics causes affected accidents analyzing the relations between causes and accidents.

Fesseha H. and Sileshi T. (2014) were attempted to describe the main causes and consequences of road traffic accidents in the Amhara region. By employing descriptive study method, secondary data were collected by Amhara National Regional State Police Commission from 2007-2011. Death rate, percentage, line and bar graphs were used to show the causes and consequences of road traffic accidents. It has been found that almost half of all crashes involved freight vehicles followed by passenger vehicles which constitute one-third of all the accidents and over half of the accidents occurred on interstate highways. According to this study, passengers accounted for the largest share of road traffic deaths across the region and pedestrians were the main victims in the urban areas. This study also revealed that mistakes created by vehicles operators are the major causes of the accidents, such as not giving priority to pedestrians, over speed, failure to stay on the right side of the road, not to maintain distance between vehicles and failure to give up the right of way to other vehicles.

\subsubsection{South Nation Nationality People Region Perspectives}

Road traffic accidents in South Nation Nationality People Region are also increasing from time to time, according 
to traffic police commission reports, road traffic accidents in South Regions are presented in the following:

Table 1: Road Traffic Accidents in South Nation Nationality People Region

\begin{tabular}{|l|l|c|c|c|c|c|}
\hline \multirow{2}{*}{ No. } & \multirow{2}{*}{ Accident severity } & \multicolumn{2}{|c|}{ Year of traffic accident records } & $\mathbf{2 0 1 6}$ & $\mathbf{2 0 1 7}$ & $\mathbf{2 0 1 8}$ \\
\cline { 3 - 7 } & & $\mathbf{2 0 1 4}$ & $\mathbf{2 0 1 5}$ & $\mathbf{2 0 1 6}$ & 582 \\
\hline 1 & Death/fatality & 371 & 464 & 523 & 523 & 608 \\
\hline 2 & Serious injury & 420 & 389 & 389 & 553 & 199 \\
\hline 3 & Light injury & 285 & 202 & 201 & 210 & 154 \\
\hline 4 & Property damage & 187 & 146 & 210 & 181 & 1543 \\
\hline 5 & Total accident & 1263 & 1201 & 1323 & 1467 & $77.2 \%$ \\
\hline 6 & Percentage share of death & $63.2 \%$ & $60.1 \%$ & $66.2 \%$ & $73.4 \%$ & \\
\hline
\end{tabular}

(Source: SNNPR Traffic Police Office (2018)

\section{Research Methodology \\ 3.1 Research Design \\ 3.1.1 Research Approaches}

A plan and procedures for research were spanning the decisions from broad assumptions to detailed methods of data collection, analysis and interpretation (Creswell, 2009). Both quantitative and qualitative research approaches were employed by the researcher. Because, the mixture of the two research approach gives better explanation as the information missed by one might be captured by the other and thus an enhanced and integrated result may emerge from the analysis. The quantitative data was employed by closed ended questions and qualitative data was employed in Semi-structured and structured interview.

\subsubsection{Methods of Data Collection and Data Source}

In attempt to address the causes and consequences of road traffic accident in the study area, and to provide possible recommendations, the researcher was used both primary and secondary data sources.

\subsubsection{Data Source}

The cross-sectional primary data for the study was collected by surveying from the sample respondents. The structured questionnaires were the basic instruments for gathering the primary data from passengers and drivers. Furthermore, the primary data was collected from pedestrian's, key informants by using structured and semistructured interview questions from the officials. As far as the secondary data was concerned, relevant data's were gathered from Gamo Gofa Zone road and transport department and Traffic police annual reports and literatures, websites (internet) <thesis, and other available sources. The study was used MS- Excel and SPSS software packages for data analysis.

\subsubsection{Sampling Technique}

The sampling techniques that used in the study were both probability and non-probability sampling methods. To collect data from passengers and drivers, the researcher was used simple random sampling techniques to ensure representativeness of the sample form the population through questionnaire. In addition, to collect the real data from key informants both positional and experiences on the theme judgmentally sampling or non-probability methods was employed.

\subsubsection{Sample Size Determination}

The total number of drivers and passengers per day were selected by probability technique using simple random sampling methods from the total 2,100, which are 93 drivers and 231 daily passengers. Whereas 5 traffic policies, 5 transport higher officials and 20 pedestrians that were assumed to be relevant to provide information at each selected corridor by using purposive/ judgment sampling technique.

The size of the population in the study area is between 1,000 and 10,000.Therefore, the sample size of the study is: $\mathrm{n}=$ ? Where $\mathrm{z}=1.96, \mathrm{p}=0.5, \mathrm{q}=1-0.5,=0.05 \mathrm{q}=0.5 \quad \mathrm{~N}=2100$

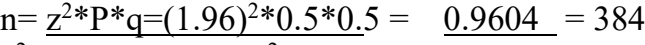

$\mathrm{e}^{2} \frac{\mathrm{z}^{2} \mathrm{p*}(1.005)^{2}}{(0.05}$

As the sample was generated from a finite population, the sample size calculated as:

$$
\mathrm{FN}=\frac{n}{1+\frac{n}{N}} \frac{384}{1+\frac{384}{2100}}=\frac{384}{1.8286}=324
$$

Were N- is the number of drivers and passengers in the study area. Depend on the formula, the sample size was calculated to be 324 , these 324 sampled drivers and passengers were selected based on simple random sampling method and well-structured questionnaire were distributed to these sampled drivers and passengers. The total sample size of the study $=$ Probability sample size + purposive sample size $=324+30=\mathbf{3 5 4}$ respondents asked. 
Table 3: Distribution of Sample Respondent's

\begin{tabular}{|l|l|l|l|c|}
\hline No & Categories & \multicolumn{1}{|c|}{ Total of the respondent } & Sampling size of the respondent & Remark \\
\hline $\mathbf{1}$ & Drivers & 600 & $600 * 324 / 2100=93$ & \\
\hline $\mathbf{2}$ & Passengers & 1500 & $1500 * 324 / 2100=231$ & \\
\hline $\mathbf{3}$ & Total & $\mathbf{2 1 0 0}$ & $\mathbf{3 2 4}$ & \\
\hline
\end{tabular}

\section{Data Analysis, Interpretation and Discussion}

\subsection{Introduction}

This section was shown that the analysis and findings of passengers and drivers on assessment of the causes of road accident and its consequences on the life and property of the community in the Gamo Gofa Zone. There were 229 passengers and 90 drivers participated in the study. Five participants were refused to complete the questionnaire out of the planned 324, which gives a response rate of $98.5 \%$. The socio - demographic, cause and consequence of the result were presented respectively.

Table 4.1: Socio- Demographic Characteristics of Drivers, Gamo Gofa Zone 2014 -2018

\begin{tabular}{|l|l|c|c|}
\hline Variables & Measurement & Number & \% \\
\hline \multirow{4}{*}{ Age } & Male & 89 & 98.9 \\
\cline { 2 - 4 } & Female & 1 & 1.1 \\
\cline { 2 - 4 } & Total & 90 & 100 \\
\hline \multirow{5}{*}{ Educational Status } & $17-29 y e a r s$ & 15 & 16.7 \\
\cline { 2 - 4 } & $30-50$ years & 68 & 75.6 \\
\cline { 2 - 4 } & 51 and above & 7 & 7.8 \\
\cline { 2 - 4 } & Total & 90 & 0.0 \\
\cline { 2 - 4 } & No education & 35 & 38.9 \\
\cline { 2 - 4 } & Grade 1-8 & 39 & 43.3 \\
\cline { 2 - 4 } & Grade 9-12 & 10 & 11.1 \\
\cline { 2 - 4 } & TVET & 4 & 4.4 \\
\cline { 2 - 4 } & Diploma & 2 & 2.2 \\
\cline { 2 - 4 } & Degree & 0 & 0.0 \\
\cline { 2 - 4 } & Masters and above & 90 & 100 \\
\cline { 2 - 4 } & Total & 35 & \\
\hline
\end{tabular}

\section{(Source: Computed from Field Survey, 2018)}

Table 4.1 was shown Demographic and Socio - economic Characteristics of Drivers in the study. Most of the respondents were male, $98.9 \%$. The majority $75.6 \%$ of Drivers were within the age category of $30-50$ years. Most of the participants completed grades $9-12,(43.3 \%)$ and grade $1-8(38.9 \%)$, while none of the Drivers had no formal education or had masters and above.

\subsection{Major Causes of Traffic Accidents Identified by Traffic Police} Fig4.1: Major Causes of Accident in Gamo Gofa Zone 2014-2018

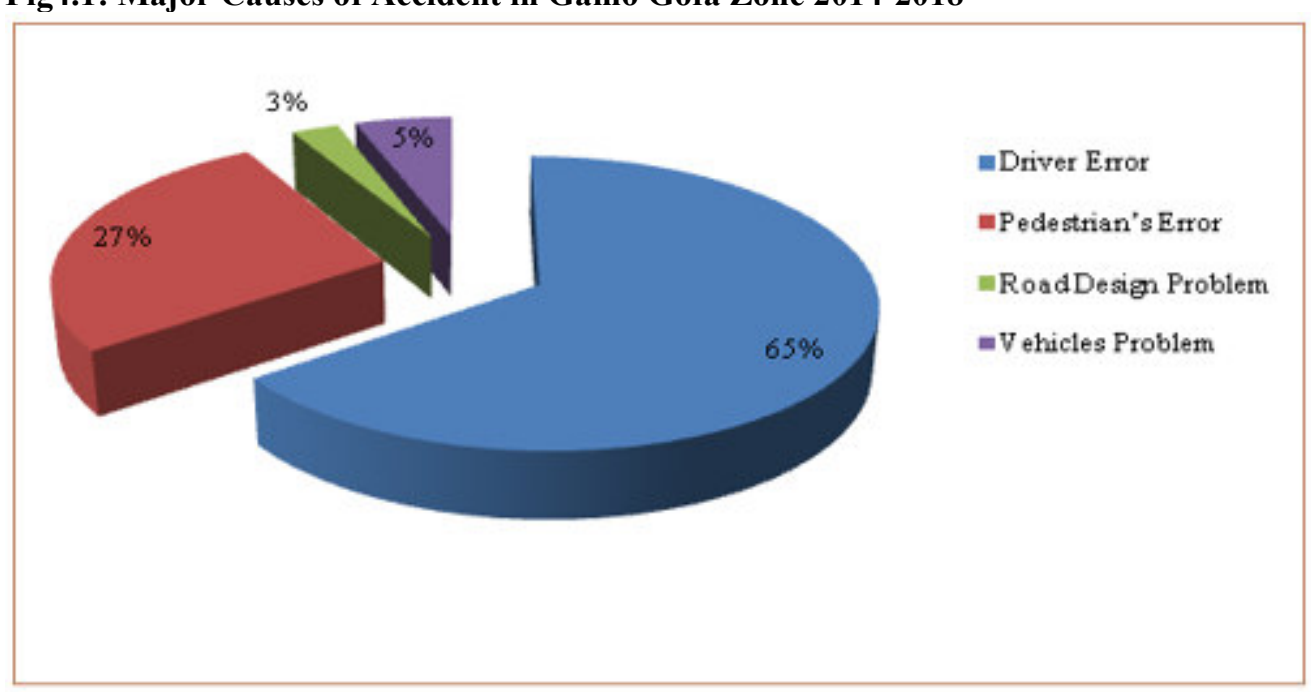

(Source: Gamo Gofa Zone Traffic Police Office, 2018) 
Table 4.2: Traffic Crash Deaths by Road User's Type

\begin{tabular}{|l|l|c|c|c|c|c|c|c|c|}
\hline \multirow{2}{*}{ Year } & \multirow{2}{*}{ Total Number of Death } & \multicolumn{2}{l|}{ Drivers } & \multicolumn{2}{l|}{ Pedestrians } & \multicolumn{2}{l|}{ Passengers } & \multicolumn{2}{l|}{ Total } \\
\cline { 3 - 12 } & & $\mathbf{N o}$ & $\mathbf{\%}$ & $\mathbf{N o}$ & $\mathbf{\%}$ & $\mathbf{N o}$ & $\mathbf{\%}$ & No & \% \\
\hline 2014 & 17 & 3 & 17.65 & 10 & 58.82 & 5 & 29.41 & 18 & 11.32 \\
\hline 2015 & 32 & 3 & 9.38 & 25 & 78.13 & 4 & 12.5 & 32 & 20.13 \\
\hline 2016 & 39 & 6 & 15.38 & 18 & 46.15 & 15 & 38.46 & 39 & 24.53 \\
\hline 2017 & 29 & 4 & 13.79 & 17 & 58.62 & 8 & 27.59 & 29 & 18.24 \\
\hline 2018 & 41 & 6 & 14.63 & 14 & 34.15 & 21 & 51.22 & 41 & 25.79 \\
\hline Average & & 4.4 & 14.17 & 16.8 & 55.17 & 10.6 & 31.84 & 159 & 100.00 \\
\hline
\end{tabular}

(Source: Gamo Gofa Zone Traffic Police, 2018)

\section{Driver's Age}

The age range of drivers involved in a crash is shown in table 8: Among these categories, drivers Within the age group 18-30 are responsible for the large number of serious injuries $72.9 \%$, for the large number of slight injures $68.06 \%$ and for the larger number of death $62.3 \%$. Age group above 51 years had the smallest share of all traffic accident types.

The implication for the highest level of death at age group 18-30 years might be due to the fact that they did not take full responsibility about their driving behavior as most of them did not marry and did not have children. However, those drivers with age category above 51 years were more minded and matured experienced that helped them to see every consequences of traffic accidents ahead.

There were $9 \%$ death occurrences for age group below 18 years. This might show the existence of an illegal driving practice below the traffic age standard for 18 years for cars.

Table 4.3: Death, Serious Injuries and Slight Injure by Driver's Age, 2014-2018

\begin{tabular}{|l|c|c|c|c|c|c|c|}
\hline \multirow{5}{*}{ Variable } & Age Category & $\begin{array}{l}\text { Total No } \\
\text { Of Death }\end{array}$ & $\mathbf{\%}$ & $\begin{array}{l}\text { Total No } \\
\text { Serious Injury }\end{array}$ & $\begin{array}{l}\text { Total No of } \\
\text { slight } \\
\text { Injury }\end{array}$ & \% \\
\hline \multirow{5}{*}{ Driving Age } & Below 18 Years & 14 & 9.1 & 8 & 4.7 & 13 & 6.8 \\
\cline { 2 - 9 } & $18-30$ years & 96 & 62.3 & 124 & 72.9 & 130 & 68.1 \\
\cline { 2 - 9 } & 31-50 Years & 35 & 22.7 & 31 & 18.2 & 39 & 20.4 \\
\cline { 2 - 9 } & Above 51 & 9 & 5.8 & 7 & 4.1 & 9 & 4.7 \\
\cline { 2 - 9 } & Total & 154 & 100.0 & 170 & 100.0 & 191 & 100.0 \\
\cline { 2 - 9 } & Average & 38.5 & & 42.5 & & 47.75 & \\
\hline
\end{tabular}

(Source: Gamo Gofa Zone Transport and Road Development Department, 2018)

\section{Driver's Education Background}

Among the Five categories of educational background those drivers with secondary school level of education were responsible for the largest share of death $31.3 \%$ and of serious injury $32.2 \%$ and of slight injury $31.0 \%$. Drivers with junior school and with above Secondary school were the second and the third categories of traffic accident accounting for $27.3 \%, 27.8$ and $29.4 \%$, respectively.

Secondary school educational level driver covered the higher of the registered accidents and has the highest share of numbers from the total number of drivers in the study area. This showed that the share of the accident was proportional when it is compared with the share of its number from the total. However, it doesn't mean that it is normal that might be registered. It means that there is a need an improvement. 
Table 4.4: Distribution of Accident Caused by Driving Experience, 20114/2018

\begin{tabular}{|c|c|c|c|c|c|c|c|c|}
\hline Variable & Driving Experience & $\begin{array}{l}\text { Total } \\
\text { Number } \\
\text { Of Death }\end{array}$ & $\%$ & $\begin{array}{l}\text { Total } \\
\text { Number } \\
\text { of } \\
\text { Serious } \\
\text { Injuries }\end{array}$ & $\%$ & $\begin{array}{l}\text { Total } \\
\text { Number } \\
\text { slight } \\
\text { Injuries }\end{array}$ & $\%$ & $\begin{array}{l}\text { Share of } \\
\text { drivers } \\
\text { from } \\
\text { total } \%\end{array}$ \\
\hline \multirow{9}{*}{$\begin{array}{l}\text { Driving } \\
\text { with } \\
\text { Experience }\end{array}$} & No driving license & 49 & 31.21 & 83 & 48.82 & 55 & 28.95 & 9.8 \\
\hline & $\begin{array}{l}\text { Less than or equal to } \\
1 \text { years }\end{array}$ & 25 & 15.92 & 24 & 14.12 & 36 & 18.95 & 8.4 \\
\hline & $\begin{array}{l}\text { Greater than } 1 \text { years } \\
\text { or Less than or } \\
\text { equal to } 2 \text { years }\end{array}$ & 24 & 15.29 & 26 & 15.29 & 23 & 12.11 & 14.2 \\
\hline & $\begin{array}{l}2 \text { years or Less than } \\
\text { or equal to } 5 \text { years }\end{array}$ & 23 & 14.65 & 22 & 12.94 & 37 & 19.47 & 24.3 \\
\hline & $\begin{array}{l}\text { Greater than } 5 \text { years } \\
\text { or Less than or } \\
\text { equal to } 10 \text { years }\end{array}$ & 22 & 14.01 & 12 & 7.06 & 31 & 16.32 & 23.3 \\
\hline & More than 10 years & 8 & 5.1 & 3 & 1.76 & 8 & 4.21 & 20 \\
\hline & Unknown & 6 & 3.82 & 0 & 0 & 0 & 0 & - \\
\hline & Total & 158 & 100 & 170 & 100 & 190 & 100 & 100 \\
\hline & Average & 22.57 & & 24.29 & & 27.14 & & \\
\hline
\end{tabular}

(Source: Gamo Gofa Zone Traffic Police Annual Report, 2018)

Table 10 was explained that drivers whose experiences more than 10 years and their share $20 \%$ represent were the cause of the least traffic accident. Drivers having more than 10 years' experience had death, serious injuries and slight injuries in 5.1 percent, 1.8 percent and 4.2 percent respectively. In opposite to this, drivers with no license and their share $9.8 \%$ are cause of the most registered accident. For instance, drivers with no license claim more than 3 out of 10 deaths and about half of serious injuries were caused by drivers with no license. This show as driving experience increases the traffic accident decreases. This secondary data did not reflect the exact relationship between traffic accident and experience of drivers with old age too.

\section{Performance of Traffic Control System in the Study Area}

Table 11 was shown that the current traffic control systems $1.3 \%$ of respondents said Excellent,3.9\% of respondents displayed that current traffic control systems is very good, $35.8 \%$ of respondents said good and $58.5 \%$, the majority of respondents, complain about the current traffic control systems in the study area. With regard to the problems of quality of road traffic management and driving licensing were the causes of traffic accident in nearly seven out of ten $69.4 \%$ respondents. While only three out of ten $30.6 \%$ respondents did not consider road traffic management and driving license as the cause for traffic accident.

Table 4.5: Performance of Traffic Control System in the Study Area.

\begin{tabular}{|l|l|c|c|}
\hline Variables & Measurement & Number & $\mathbf{\%}$ \\
\hline Perception of traffic control system & Excellent & 3 & 1.3 \\
\cline { 2 - 4 } & Very Good & 9 & 3.9 \\
\cline { 2 - 4 } & Good & 82 & 35.8 \\
\cline { 2 - 4 } & Weak & 134 & 58.5 \\
\cline { 2 - 4 } & Missing & 1 & 0.4 \\
\cline { 2 - 4 } & Total & 229 & 100.0 \\
\hline \multirow{2}{*}{$\begin{array}{l}\text { Relationship of traffic management with } \\
\text { accident }\end{array}$} & Yes & 759 & 30.4 \\
\cline { 2 - 4 } & No & 229 & 100.0 \\
\cline { 2 - 4 } & Total & & \\
\hline
\end{tabular}

(Source: Computed from Field Survey, 2018).

Safety Conditions of Passengers

Table 4.5 shows that the majority of the surveyed passengers about availability of traffic sign, i.e. $60.3 \%$ confirmed that the lack of traffic signs and behavior of pedestrians can be cause of road accident, $39.7 \%$ of respondents said that lack of traffic signs and behavior of pedestrians alone cannot be a cause of road accident.

Towards Knowledge on traffic sign, signals and road marks: $44.1 \%$ of the respondents have correctly perceived traffic sign, signals and road marks when they move on the street and cross the road. However, the majority respondents account for $55.9 \%$ are not correctly perceive traffic sign, signals and road marks when they move on the street and cross the road. 


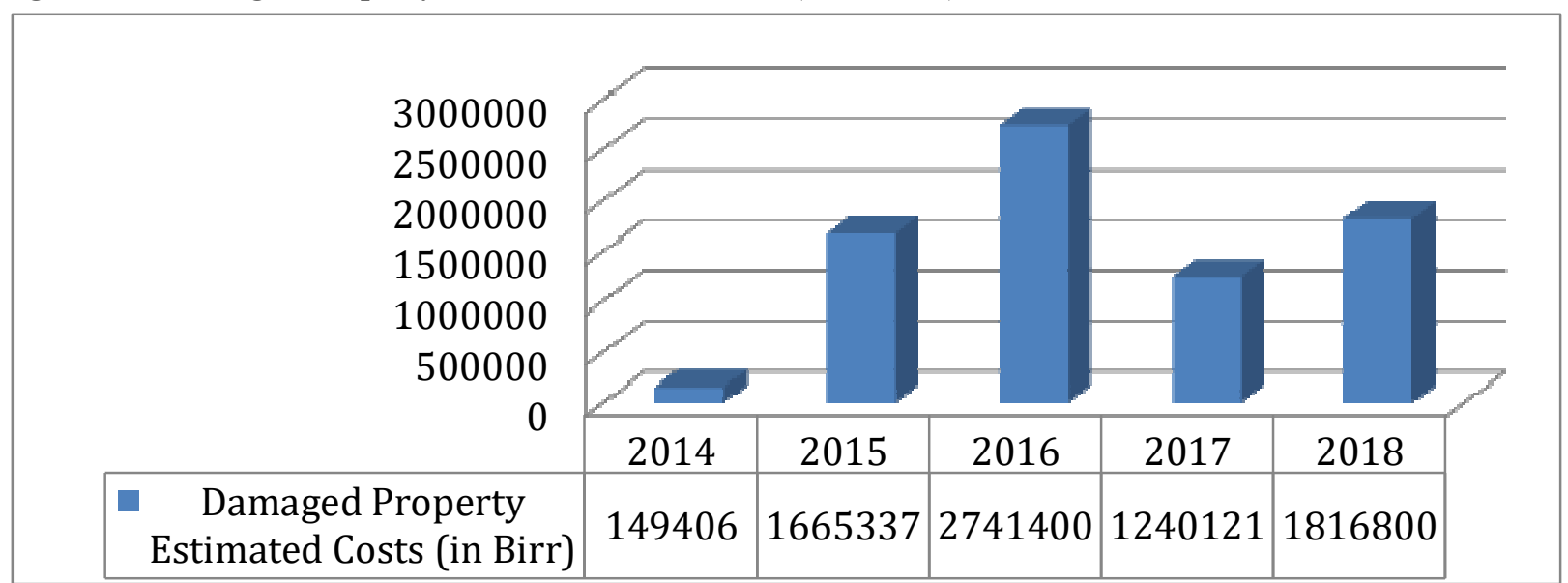

\section{Source: Gamo Gofa Zone Traffic Police Annual Report (2014/2018).}

Based on the data obtained from traffic police the social impacts of road traffic accident in the study area categorized as fatal (death), serious and light injury. The above table shows that in Gamo Gofa Zone the total damage on property accidents, estimated8, 957,723.00 in Birr five years (2014-2018).

Plate: 5: Property Damage by Traffic

Accidents in the Study Area

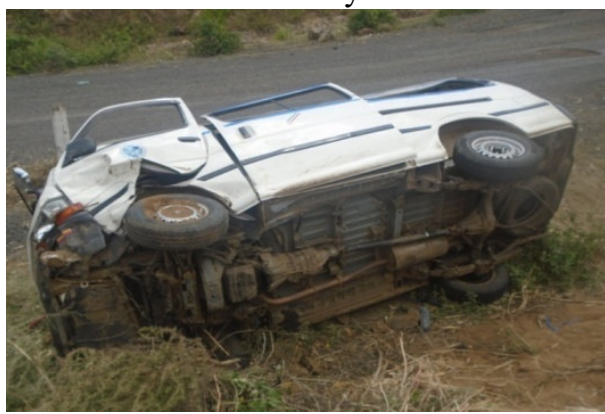

Plate7: Property Damage by Traffic Accidents in the Study Area

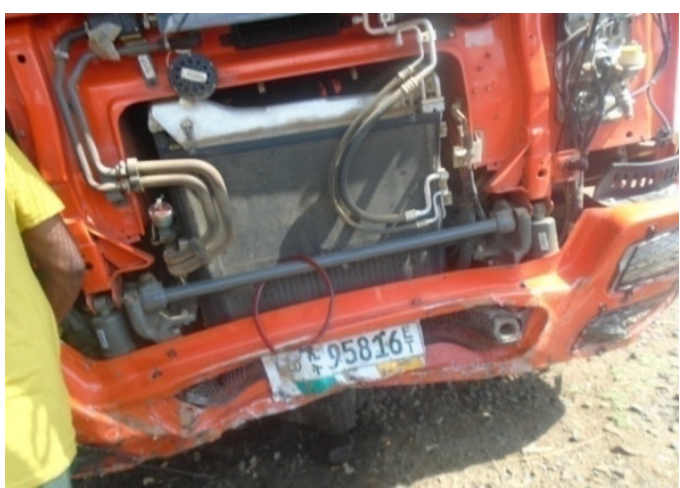

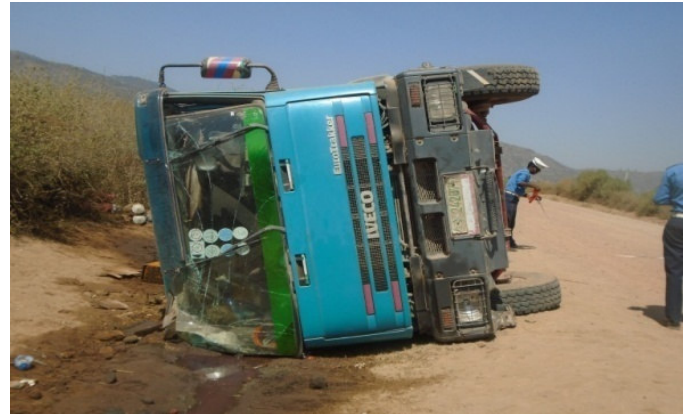

Plat 8: property Damage by traffic accidents in the study Area

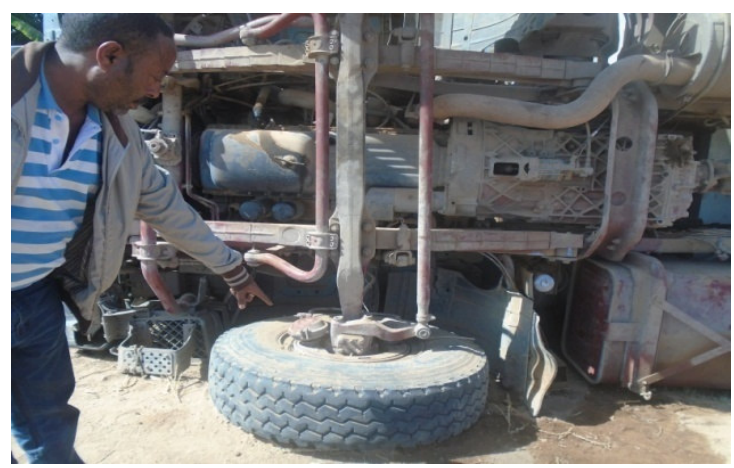

(Source: Gamo Gofa Zone Traffic Police, 2018)

The consequences of road traffic accidents have both social and economic impacts. One of the major economic impacts caused by road traffic accidents is damage to property. 
Table4.6: Traffic Accidents by Age Group at (2014-2018).

\begin{tabular}{|l|l|l|l|l|l|l|l|}
\hline \multirow{2}{*}{ Age Group } & \multicolumn{7}{|c|}{ Number of Accidents } \\
\cline { 2 - 9 } & $\mathbf{2 0 1 3 / 0 1 4}$ & $\mathbf{2 0 1 4 / 0 1 5}$ & $\mathbf{2 0 1 5 / 0 1 6}$ & $\mathbf{2 0 1 6 / 0 1 7}$ & $\mathbf{2 0 1 7 / 2 0 1 8}$ & Total & Share \% \\
\hline below 18 years & 2 & 6 & 2 & 1 & 5 & 16 & 2.48 \\
\hline 18-30 years & 70 & 72 & 94 & 91 & 98 & 425 & 65.99 \\
\hline 31-50 years & 30 & 45 & 30 & 39 & 33 & 177 & 27.48 \\
\hline Above 51 years & 6 & 5 & 2 & 6 & 7 & 26 & 4.04 \\
\hline Total & $\mathbf{1 0 8}$ & $\mathbf{1 2 8}$ & $\mathbf{1 2 8}$ & $\mathbf{1 3 7}$ & $\mathbf{1 4 3}$ & $\mathbf{6 4 4}$ & 100 \\
\hline
\end{tabular}

(Source: Gamo Gofa Zone Traffic Police Annual Report, 2014/2018)

In the above table 23 was shown that the road traffic accident hazard is very high among the work- force 1830 age group, which covers for $65.99 \%$ of all casualties in the study area. A road accident is very low below 18 years age. As interviewees' explanation, below 18 years old persons are not active transport users in the study area.

\section{Conclusions and Recommendations}

\subsection{Conclusions}

It is accredited fact that of all modes of transportation, road transport is the nearest to people in both developing and developed countries. Its major advantage compared with others, its flexibility which across it to operate from door to door over short distances at the most competitive price. However, these merits of motorizations were not without negative effects. The boost in road transportation has placed an extensive burden on the people's lives. Road traffic accidents have turned out to be a huge global public health and development problem. The aim of this study is to ascertain the causes and the consequences of road traffic accident, and in order to achieve this objective the study primarily employed a descriptive data analysis method.

The results obtained throughout the assessment from the traffic police and field survey data indicated that road traffic accident is a serious problem in the study area. The extent and amount of road traffic accidents are following an increasing trend especially death, throughout the study period. This indicates that the attention on severity of traffic accident by Zone administration, transport sectors, and traffic Police departments is very poor.

As has been seen from the result and presentation part of the thesis, the majority of traffic accidents were occurring due to driver's error that accounts for $65 \%$ of traffic accident followed by $27 \%$ of pedestrian errors.

An analysis on drivers revealed that over-speed driving, not ceding priority to pedestrians and tiredness or sleepiness while driving as the main cause of traffic accident. In addition, even most of drivers are using their seat belts, significant numbers of drivers are not using seat belts or using sometimes.

On the other side, the majority of traffic accident due to the pedestrian's wrong crossing of the road, poor manner in giving priorities to vehicles and their carelessness are the significant causes for road traffic accident in the study area. The study showed that awareness of pedestrians and passengers on traffic safety rule and regulation is very poor. The behavior of pedestrian's passengers is also causing loss of lives and a lot of material damage.

Another causes of road traffic accident is the lose controlling and enforcement practices of traffic polices and weak quality provision of driving license by transport offices in the study area. The qualitative finding shows, traffic police are misbehaving to get illegal money out of their authority by missing legal implementing on the rules and regulation of traffic management.

The above causes show that most of the traffic accidents are related to the behavior and ethical problems of drivers and pedestrians. The study indicates, drivers' background, pedestrian experience and the traffic management system in the zone are influencing factors for the behavior of drivers. This is supported by the fact that drivers education, age and years of experience had influenced their behavior. Moreover, there is an awareness gap of pedestrians and passengers in traffic safety management. The provision of driver license is also very poor. Transport sector provides the driving license for those who asks and wants regardless of its consequences. In addition, traffic controlling, inspection and enforcement are very losing in the study area.

In most parts of the study area, official road accident statistics make a distinction between three levels of injury severity: fatal, serious and slight. This study concludes that all fatal, serious and light injuries are occurring in the study area due to road traffic accident. These injuries are death, disability, loss of household income due to death of productive household members and property damage. This implies that death, huge amount of property damage and social crises are the most prominent consequences of road traffic accident in the zone.

\subsection{Recommendation}

Remedial actions in traffic management system to reduce traffic accidents that should be undertaken in the study area are recommended below by the researcher.

Administrations at different levels have the responsibility of controlling and evaluating the transport sectors. Transport sectors of the study areas should implement their duties by full responsibility and accountability in accordance with transportation rules and regulations. The transport sector should strongly work on the 
development of drivers' capacity including making them aware about road safety rules and regulations.

Most of drivers were academically at lower level having elementary and secondary schooling. Hence, public transport driver licensed individuals should be at least secondary school and above completed in their educational level. Moreover, traffic and safety management should be included in the curriculum in order to educate school society about the hazardous of traffic accident. The SNNPR administration should force the education sectors to include the road safety and traffic management system in the curriculum of primary schools.

Region transport Bureau should capacitate transport sector and traffic police official's knowledge and skills. Moreover, it should promote them by necessary allowances in order to perform their responsibilities with responsiveness.

\section{Regular Awareness Creation}

Transport officials and traffic police are expected having specialized and scheduled awareness creation plan in schools, religious institution, in market areas and using local media in order to bring attitudinal change on road safety and traffic management.

Attaching different posters by traffic club students, traffic committee and interested individuals from the society to train pedestrians and passengers are actions that should be exercised in the above institution to bring change in knowledge and skills of the society.

To improve awareness creation and positive behavior of pedestrians and passengers, concerned bodies should adapt mechanism to the specific need of a segment of the population. For example the awareness creation mechanisms should take into consideration of gender, age, users' traffic experiences and education of pedestrians and passengers.

\section{Road Traffic Regulation Enforcements}

Government has a responsibility to administer and manage transport service delivery in order to sustain socioeconomic and safety benefits of it. Safety is the main concern of this paper that the researcher focused. Gamo Gofa Zone transport office should check the driving license provision system, training institution capacity and their implementation. Today, in Gamo Gofa, illegal driving license is becoming a source of illegal income generation. Traffic enforcement has better to undertake not only on the law breaker drivers, but also on the law breakers of pedestrians and passengers. Standard traffic rules and regulation should be practiced on all persons without partiality including higher government officials.

It is expected that setting an accountability mechanism that have both incentive and punishment scheme for performance of safety activities. Engagement of traffic police in development of the accountability program is including provision of capacity building by training and experience sharing in order to develop implementation capacity.

Transport infrastructures like traffic signals have better to be constructed, maintained and replaced on the necessary places on time.

Generally, the Zone, towns and woreda administrations are expected to take essential evaluation for each problem and take alternative corrective actions in order to reduce the accident, fear and threat of the society on public transport service delivery.

\section{References}

Abdul-Rahaman, H (2014), Identification of Factors that Cause Severity of Road Accidents in Ghana: a Case Study of the Northern Region Science Journal of Applied Mathematics and Statistics M.sc, Thesis Department of Statistics, Mathematics and Science Tamale Polytechnic.

Afukaar, F(2003), Speed control in developing countries: issues, challenges and opportunities in reducing road traffic From<injuries. Inj Control Saf Promot.10: 77-81. 10.1076/icsp.10.1.77.14113>.

Akongbota, J (2011), Reducing accidents on our roads. Retrieved December 21, 2011, from the government of Ghana official portal web site: <http://www.ghana.gov.gh/index.php>

American Institute of Certified Public Accountants (AICPA), (2012), Audit Guide: Audit Sampling. NY: AICPA. America: New York.

American Public Transport Association,(2014),Economic Impact of Public Transportation Investment (ed),America.

Ampanozi,G.Benosetal, (2011), .Analysis of Fatal Motor Vehicle Collisions: Evidence from Central Macedonia, Greece:Hippokratia.

Anteneh, K Sebsbie BSN (2015), Road Traffic Accident Related Fatalities in Addis Ababa City, Ethiopia.

AtnafSeged,Kifle(1996),Road Safety management Crisis in Ethiopia. Unpublished

Bitew, Mebrahtu (2002),Taxi Traffic Accidents in Addis Ababa: CausesTemporal and Spatial Variations and Consequences. A.A.U.(Thesis M.A.in Human Geography),Ethiopia: Addis Ababa.

Cater N,Walker,P (1998), World Disasters Report. (Eds.)Oxford University Press, Britain. 
Chong, M., A. et al. (2005), "Traffic Accident Analysis Using Machine learning Paradigms."Informatica 29(1).

Creswell,(2009),Research Methodology Methods and Techniques, CSA (Central Statistics Authority).(2007) The Population and Housing Census of Ethiopia. Statistical Data of SNNPR, Addis Ababa, Ethiopia.

Daniel,(2014),Road Traffic Accidents Increasing in Ethiopia.

Dinye, R (2013), The Significance and Issues of Motorcycle Transport in the Urban Area.

Economic Impact of Public Transportation Investment (2014), American Public Transport Association(ed)

Ethiopian Road Transport Authority (ERA) (2013), Annual Report.Addis Ababa Ethiopia.

Fanueal,S (2006),Analysis of Traffic Accident in Addis Ababa, Traffic Simulation, Unpublished MA Thesis Addis Ababa University (AAU).Ethiopia.

Federal Police Commission, (2015), Annual Reports, Addis Ababa,Ethiopia.

Fesseha,HAndSileshi, T (2014),Road traffic accident: The neglected health problem in Amhara National Regional State, M.sc Thesis Addis Ababa, Ethiopia.

Fikadu, M (2015),Road Traffic Accident: Causes and Control Mechanisms: In Addis Ababa Citya Thesis Presented to the School of Graduate Studies, Addis Ababa University.

Gamo Gofa Zone Transport and road development department, 2015, Annual Reports.

Gamo Gofa Zone Traffic police department 2015,Annual Reports.

Gebrechristos, N (2014), ,,Trends and Factors Affecting the Use of Non-Motorized Modes of Transportation in Hawassa City, Ethiopia. Gifford ,J.L (2003), Flexible Urban Transportation Arlington.

GIRMA, (1996), Basic Transport Management and Profit- ability; AAU Unpublished.

Getahune, Y(2016),Causes and Consequence of Traffic Accident in Oromia Special Zone: A Case Study of Addis Ababa-Sululta CorridorM.sc Thesis. in ECSU, Ethiopia.Un published.

Getnet, M (2009), Applying data mining with decision tree and rule induction techniques to identify determinant factors of drivers and vehicles in support of reducing and controlling road traffic accidents: the case of Addis Ababa city. Addis Ababa Addis Ababa University.

Getu, Sagni (2007), Causes of Road Traffic Accidents and possible Counter Measures on Addis AbabaShashamane Roads', MSC.Thesis, Addis Ababa University.

Haile Mekonnen, FDemeke, L(2014),Analysis of Factors that Affect Road Traffic Accidents in Bahir Dar City, North Western Ethiopia. Science Journal of Applied Mathematics and StatisticsM.sc Thesis.in Addis Ababa Thesis Presented to the School of Graduate Studies, Addis Ababa University, Ethiopia.

Hagere, Y(2014),Challenge and prospects of traffic management practices of Addis Ababa city Administration, a Thesis Presented to the School of Graduate Studies, Ethiopia, Addis Ababa University.

HCM, (2000),Pedestrians Geographic Design Manual: Transportation Research Board, American, Washington DC Iles, R 2005,Public Transport in Developing Countries, Elsevier Ltd. International Fund for Agricultural Development, 2011,Tools for Preparing a Survey. Rome(Italy):IFAD.

Komba,(2006), Risk Factors and Road Traffic Accidents in Tanzania: A Case Study of Kibaha District Master Th esis in Development Studies, Specializing In Geography Department of Geography, Trondheim Norwe gian University of Science and Technology (NTNU), Tanzania.

Kothari, C.R, (2004), Research Methodology Methods and Techniques, New Delhi, New Age International Publishers.

Kothari, C.R, (1990), Research methodology, Methods and techniques. New Ltd age international publishers India: Jaipur. University of Ajasthan.College of Commerce. Viewed Jan. 2017, from

$<$ (http://www2.hcmuaf.edu.vn/data/quoctuan/Research\%20Methodology\%20-\%20Methods\%20and\%20Techniq ues\%202004.pdf) >.

LNicajet. Al.(2006),Motor vehicle crash pedestrian deaths in New York City: the plight of the older pedestrian. InjuryPrevention. America.

Lankarani et.al, (2013), The second international on reducing burden of traffic accidents, Shiraz, Iran. Journal of Injury and Violence.

Mcknight\&Bahouth 2011, .Revised characteristic of police report.

Yoseph,Asrat (2003),Descriptive Analysis of Road Traffic Crashes.

Yayeh, Addis (2003), The Extent, Variations and Causes of Road Traffic Accidents in Bahirdar, A Thesis Presented to the School of Graduate Studies, Addis Ababa University. 